\title{
Synthesis and Densification of Tungsten-Brass Composite by Mechanical Alloying
}

\author{
Kahtan S. Mohammed1, Baba Gowon ${ }^{12^{*}}$, Shamsul Baharin Bin Jamaluddin1, \\ Zuhailawati Hussain $^{3}$, Polycarp Evarastics ${ }^{1}$ \\ ${ }^{1}$ School of Materials Engineering, Universiti Malaysia Perlis (UniMAP), D/A Pajabat Pos Besar, Kangar, Malaysia \\ ${ }^{2}$ Department of Metallurgical and Materials Engineering, Federal Polytechnic, Idah, Nigeria \\ ${ }^{3}$ School of Materials and Mineral Resources Engineering, Engineering Campus, Universiti Sains Malaysia, \\ Nibong Tebal, Malaysia \\ Email: ${ }^{*}$ babagowon@yahoo.com
}

Received 18 July 2015; accepted 28 August 2015; published 1 September 2015

Copyright (C) 2015 by authors and Scientific Research Publishing Inc.

This work is licensed under the Creative Commons Attribution International License (CC BY). http://creativecommons.org/licenses/by/4.0/

(c) (i) Open Access

\section{Abstract}

Fabrication of full-density $W$-brass composites is very difficult to achieve because of evaporation of zinc, insolubility of $W$ and brass and compacts expansion. In this study, to achieve full-density W-brass composites, mechanical alloying (MA) and activated sintering process were utilized. Mechanical coating of $\mathrm{W}$ with $\mathrm{Ni}$ using high energy planetary ball mill was carried out. The milling was divided into two stages: to alloy and modify the surface of $\mathrm{W}$ with $\mathrm{Ni}$ for enhanced activation. The microstructure of the milled powders and sintered compacts, elemental composition and phases present were studied by using scanning electron microscopy (SEM), energy dispersive X-ray spectroscopy (EDX) and X-ray diffraction (XRD) respectively. As-received powder compacts was also sintered under the same condition for comparison purpose. The effects of milling time on the microstructure, sinterability and the hardness of the composites were investigated. It was observed that the samples produced from $8 \mathrm{~h}$ milled powder had the highest relative sintered density $(98 \%$ TD) and microhardness $(234 \mathrm{Hv})$. On the other hand, the samples from the as-received powders expanded and had a relative sintered density of $(67 \%$ TD) and microhardness as low as $24 \mathrm{Hv}$. The significance of this study is the possibility of producing $\mathrm{W}$-brass composites as a cheaper alternative to $\mathrm{W}$-Cu composites.

\section{Keywords}

W-Brass, Mechanical Alloying, Microstructure, Expansion, Hardness

\footnotetext{
"Corresponding author.
}

How to cite this paper: Mohammed, K.S., Gowon, B., Jamaluddin, S.B.B., Hussain, Z. and Evarastics, P. (2015) Synthesis and Densification of Tungsten-Brass Composite by Mechanical Alloying. Open Journal of Metal, 5, 27-36. 


\section{Introduction}

Tungsten-copper (W-Cu) and tungsten-copper alloys have received a serious attention by researchers due to the high melting point, high density, excellent high-temperature strength, low coefficient of expansion of $\mathrm{W}$ and high electrical and thermal conductivity of $\mathrm{Cu}$ [1]. W-Cu composites are used for the production of electrodes, heavy duty electronic contacts, in radiation shielding, kinetic energy penetrators and ammunitions, heat sinks in high power microelectronics, gyroscope rotors and divertor plates for fusion reactors [2]-[5].

$\mathrm{W}$-Cu composites exhibit mutual insolubility or minimal solubility and poor wettability of $\mathrm{W}$ by $\mathrm{Cu}$. As a result of this, fabrication of $\mathrm{W}-\mathrm{Cu}$ composites with high sintered density and homogeneous microstructure is difficult [6]-[8]. There is also a large difference in the melting point of $\mathrm{W}\left(3410^{\circ} \mathrm{C}\right)$ and $\mathrm{Cu}\left(1083^{\circ} \mathrm{C}\right)$. Due to this disparity, traditional metal-casting process and alloying cannot be used to produce $\mathrm{W}$-Cu composites [9].

To achieve high sintered density, many techniques have been adopted by researchers. Transition metals like nickel, when added in small amount to $\mathrm{W}$-Cu composites, can lower the activation energy of sintering, thereby reducing the sintering temperature. $\mathrm{Ni}$ improves the wettability and adhesion of $\mathrm{W}$ and $\mathrm{Cu}$ that results to the production of nonporous composites [10]-[12]. Another technique that is widely used to enhance densification is mechanical alloying (MA). MA is a powder metallurgy process that was developed in the mid-1960s by the International Nickel Company (INCO) as a solid route for introducing and retaining fine refractory oxide particles in high temperature alloys mainly for gas turbine applications [13]-[15]. It is a solid-state powder processing method through repeated welding, fracturing, and rewelding of powder particles in a high energy ball mill [16]. MA leads to high plastic deformation of the trapped powders as a result of ball-to-ball and ball-to-wall collision, resulting in the dislocation of the powder particles. The green compacts produced from MA powders are subjected to thermal energy in a sintering process to produce a high density material [17]. This process has proved to be essential in the fabrication of composites that are difficult to produce by using conventional processes as a result of high vapour-pressure or disparity in the melting temperature of the components. The process of mechanical alloying of W-Cu composites results in the dissolution of small amount of $\mathrm{Cu}$ into $\mathrm{W}$ causing a shift in the $\mathrm{W}$ peak in the XRD analysis [18].

Kim and Moon [19] sintered nanostructured MA powders of W-Cu at $1000^{\circ} \mathrm{C}, 1200^{\circ} \mathrm{C}$ and $1300^{\circ} \mathrm{C}$ and obtained a relative sintered density of more than $95 \%$ by particle rearrangement via liquid phase sintering and the greatest homogeneity of microstructure was attained at the sintering temperature of $1200^{\circ} \mathrm{C}$. Solid state and liquid phase sintering of mechanical alloyed W-20 wt\% Cu was studied by Maneshian and Simchi [20]. Their study revealed that there was a meaningful relationship between the sinterability and milling time; higher hardness and conductivity were obtained by prolonged MA and SPS due to lower W-W contiguity of MA powders, a decrease in the melting point of $\mathrm{Cu}$ up to $145^{\circ} \mathrm{C}$ was achieved and a more homogeneous distribution of $\mathrm{Cu}$ prevented the formation of $\mathrm{Cu}$ pool during liquid phase sintering thereby increasing the homogeneity of the sintered compacts. A study of nanostructured $\mathrm{W}$-Cu electrical contact materials processed by hot isostatic process was carried out by Tsakiris et al. [21]. In their study, W-Cu-Ni with Cu content ranging from 20 - $40 \mathrm{wt} \%$ and $1 \mathrm{wt} \%$ $\mathrm{Ni}$ were mechanically alloyed for 10 and $20 \mathrm{~h}$, and they achieved a high sintered density of $89 \%$ and homogeneous microstructure, higher Vickers hardness values were obtained from the compacts produced from the powders milled for $20 \mathrm{~h}$ due to the reduced particle size, uniform distribution of the intermetallic phases as well as the presence of $\mathrm{W}$ which was the harder phase. It was also observed that the composite with the highest $\mathrm{Cu}$ phase $(40 \%)$ and shorter milling time $(10 \mathrm{~h})$ had better physical, mechanical and functional properties. Relative sintered density of 99.6\%, tranverse rupture strength of 1400.9 Mpa, Rockwell C hardness of 45.2, thermal conductivity of $196 \mathrm{~W} / \mathrm{mk}$ homogeneous and fine microstructure was obtained in W-15Cu alloys prepared by mechanical alloying and SPS process was carried out by Shi et al. [22]. 97.0\% and above relative sintered density at a shorter milling time of $8 \mathrm{~h}$ was achieved when investigation of MA effects on $\mathrm{W}$-20Cu composites was carried out by Kecskes et al. [23].

In this study, $50 \mathrm{~W}-48$ br (brass)-2Ni was produced by MA. The effect of MA on the densification, microstructure, porosity and hardness was carried out. W-brass composite is a cheaper alternative to $\mathrm{W}$-Cu composites, but before now, no literature is available on its densification by mechanical alloying.

\section{Experimental Procedure}

In this study, elemental W (99.9\% purity), prealloyed brass (99.9\% purity) and $\mathrm{Ni}(99.9 \%)$ and particle size of $12 \mu \mathrm{m}, 45 \mu \mathrm{m}$ and $45 \mu \mathrm{m}$ respectively were used. The composition of the powder mix was $50 \mathrm{~W}-48 \mathrm{br}$ 
(brass)-2Ni. This composition was mechanically alloyed for 0 h, 8 h, 12 h and 14 h. The control sample was produced from the powder that was not milled $(0 \mathrm{~h})$. The powder for the control sample was manually mixed in a beaker for about 30 minutes to reduce the effects of density variation. The MA was done with an attritor milling machine (Fritsch Pulverisette) under pure argon atmosphere with the speed of $350 \mathrm{rpm}$. Steel jar and steel balls of $5 \mathrm{~mm}$ diameter and a powder to ball weight ratio of 1:10 was used.

Because $\mathrm{Cu}$ and $\mathrm{Ni}$ are completely miscible in both the liquid and solid state, the MA was done in two stages. In the first stage, $\mathrm{W}$ and Ni were milled for $4 \mathrm{~h}$, and in the second stage, prealloyed brass was added and milled for another $4 \mathrm{~h}$. The first stage is the mechanical coating of $\mathrm{W}$ with Ni. This was done to ensure that Ni was available to be segregated at the $\mathrm{W}$ grain boundaries to enhance the wettability and activate the process. Also, in the powders milled for $12 \mathrm{~h}, \mathrm{~W}$ and Ni was milled for $6 \mathrm{~h}$, brass was added and milled for another $6 \mathrm{~h}$. The same process was repeated for the powders milled for $14 \mathrm{~h}$. Small powder mixture were taken at each stage for analysis. Different techniques were used for powder characterization. SEM was used to analyze particle morphology, chemical analysis by EDX and the phases present was analyzed by XRD.

Both the as-received and the mechanically alloyed powders were introduced into a permanent mould and pressed with a mechanical press (Caver, made in USA) at the pressure of 350 Mpa to produce the green compacts. The green compacts have a diameter of $10 \mathrm{~mm}$ and $3 \mathrm{~mm}$ to $4 \mathrm{~mm}$ height. The green density was calculated using weight per volume ratio. The green compacts were sintered using Carbolite tube furnace at the temperature of $1150^{\circ} \mathrm{C}$, heating and cooling rate was $5^{\circ} \mathrm{C} / \mathrm{min}$. and $10^{\circ} \mathrm{C} / \mathrm{min}$. respectively and were isothermally held for $2 \mathrm{~h}$. The sintering was done under pure hydrogen atmosphere. Archimedes method and weight per volume ratio was used to determine the sintered density. The sintered samples were ground with 600, 800 and 1200 grades of emery papers and polished with $0.5 \mu \mathrm{m}$ and $0.3 \mu \mathrm{m}$ alumina suspension on a polishing cloth. The samples were then rinsed with distilled water and dried with compressed air. SEM and optical microscope was used to study the microstructure while the phases present and the composition was analysed by XRD and EDX respectively. Leco microhardness testing machine was used to determine the hardness.

The sinterability of the compacts was expressed in terms of densification parameter (DP);

$$
\mathrm{DP}=\frac{\text { sintered density }- \text { green density }}{\text { theoritical density }- \text { green density }}
$$

The porosity of the green and sintered compacts was determined by the following relations:

$$
\begin{aligned}
& \text { Porosity }(\text { green })=\frac{\text { theoritical density }- \text { green density }}{\text { theoritical density }} \times 100 \\
& \text { Porosity }(\text { sintered })=\frac{\text { theoritical density }- \text { sintered density }}{\text { theoritical density }} \times 100
\end{aligned}
$$

\section{Results and Discussion}

\subsection{Sintered Density}

The relation between relative sintered density and milling time, and the densification parameter is shown in Figure 1. There were significant differences between the sintered density of the as-received compacts and the mechanically alloyed compacts. The highest density of $98 \% \mathrm{TD}$ was attained at $8 \mathrm{~h}$ milling time. As the milling time was extended to $12 \mathrm{~h}$, the density decreased to $97 \%$ TD and decreased further to $94 \%$ TD after $14 \mathrm{~h}$. The lowest density of $67 \% \mathrm{TD}$ (lower than the relative green density) was achieved in the as-received compact under the same condition.

The DP for the as-received compact is negative as shown in Figure 1(b). The compact milled for $8 \mathrm{~h}$ has the highest DP value. The densification results show that MA influences the sinterability of W-brass composites. As a result of MA, the W-brass particle undergoes severe plastic deformation to produce nanocrystalline powders. These nanocrystalline powders enhance the diffusion rate, reduce the diffusion distance and an extention in the solid solubility [20].

The solubility of $\mathrm{W}$ in brass is negligible, hence, during liquid phase sintering, densification is limited to rearrangement and solid state sintering of $\mathrm{W}$ network skeleton structure [3]. In agreement with the work of Kecskes et al. [23], the fineness of $\mathrm{W}$ and homogeneous dispersion of the brass phase as a result of ball milling 


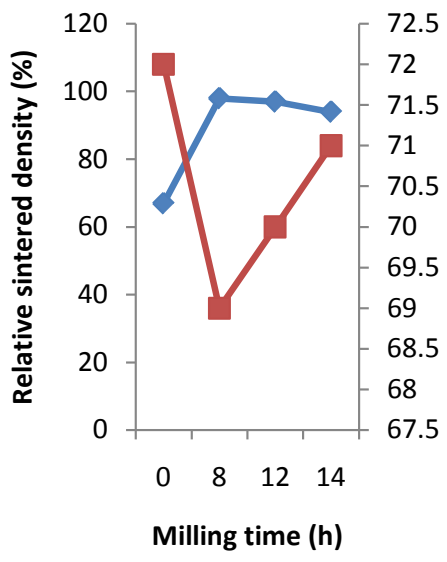

(a)

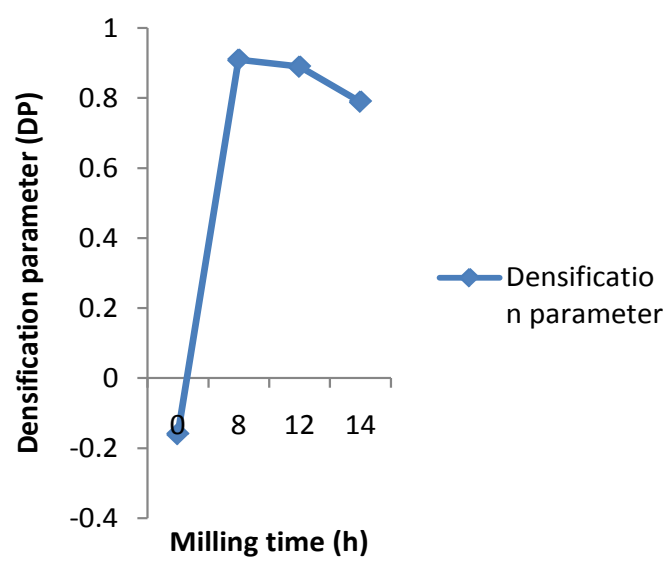

(b)

Figure 1. (a) Relative density with time; (b) densification parameter with time.

greatly influence the sinterability of W-brass composites in both solid and liquid phase sintering. MA also aids in increasing the solubilty of brass in $\mathrm{W}$ and decreased the melting point of brass. The high relative sintered density obtained in the compacts milled for $8-14 \mathrm{~h}$ can be attributable to reduced particle size, enhanced particle rearrangement due to the formation of liquid brass, reduction in the diffusion distance and the activating role of Ni. The relation between the porosity and milling time is shown in Figure 2. It is obvious from this results that porosity is directly related to the sintered density. The sample milled for $8 \mathrm{~h}$ with the highest density has the lowest porosity (2.75\%). The as-received compacts have the highest value of porosity (32\%) and the lowest density. As the milling time increased beyond $8 \mathrm{~h}$, the porosity slightly increased to $3 \%$ and $6 \%$ for 12 and $14 \mathrm{~h}$ respectively.

When Kecskes et al. [23] synthesized W-Cu composites by MA from 15 min 48 h, the composites milled for $8 \mathrm{~h}$ also had the highest sintered density and beyond this time, homogeneous fine particles began to coarsen with a corresponding increase in residual porosity, leading to decrease in density and hardness. Oxide build-up on the superfine reactive powder surfaces is another problem of longer milling time. Other factors that might be responsible for the decrease in sintered density after prolonged milling beyond $8 \mathrm{~h}(12-14 \mathrm{~h})$ are defects like stored internal strain, dislocation, and closed micro pores caused by welding, fracturing and rewelding of the constituent powders [24].

In the as-received compact with the lowest density, the negative value of DP indicates compact expansion or swelling. While sintering Ti-Ni shape memory alloy, Igharo and Wood [25] discovered that the decrease in sintered density than the green density was as a result of Kirkendall diffusion, particle segregation and expansion due to penetration of the liquid phase into the capillaries. Koo et al. [26] investigated the metallurgical and mechanical properties of brass hollow spheres by sintering at the temperature of $800^{\circ} \mathrm{C}-930^{\circ} \mathrm{C}$ and discovered that the evaporation of $\mathrm{Zn}$ increases with increase in sintering temperature because of the high vapour pressure of zinc. In the sintering of brass, it is common to lose zinc because of the different vapour pressure of $\mathrm{Cu}$ and $\mathrm{Zn}$ [27]. During the LPS of the as-received compact, the diffusion between W and brass will initially lead to compositional variations. Subsequently, a homogeneous structure results with a density lesser than the theoretical value. As the compact expands, the porosity increases with a corresponding decrease in density. The negative value of DP indicates expansion while positive value indicates shrinkage [28]. During the heating up stage (at solid state sintering), non-uniform diffusion takes place. In the radial direction, interdiffusion between $\mathrm{W}$ and brass takes place, while in the axial direction, diffusion will be between the same powder particles (W-W and brass-brass). Because brass diffuses faster than $\mathrm{W}$, the brass will lose some atoms, thereby creating diffusional porosities at the prior brass sites. In the axial direction, W-W self diffusion causes neck growth, followed by densification. As the sintering enters into the LPS stage, the transient liquid that appeared on the W side on the initial W-brass interparticle contacts penetrates along capillaries with those formed during the earlier solid state diffusion stage. This causes expansion of the compact, leaving behind pores in the prior $\mathrm{W}$ particle region [25].

In this study, Ni was added as an activator. Boonyongmaneerat [29] sintered W-Cu composites with and without $\mathrm{Ni}$ and $\mathrm{Fe}$ and found that the compacts containing additives had higher sinterability than pure W com- 


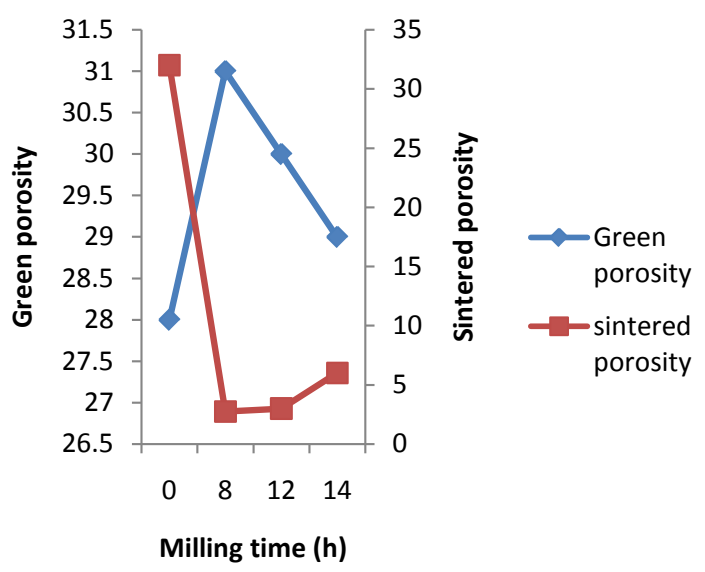

Figure 2. The relation between green porosity and sintered porosity with milling time.

pacts. $\mathrm{Ni}$ is completely soluble in the brass matrix. By the addition of activators that are soluble in the liquid phase, densification and grain growth through solution precipitation are enhanced [19].

The aim of splitting the milling process into two stages is to modify the surface of $\mathrm{W}$ for enhanced wettability and also to alloy $\mathrm{Ni}$ with $\mathrm{W}$ to avoid complete dissolution of $\mathrm{Ni}$ in brass, which could slow the activation process. In the second stage, when prealloyed brass was added to the alloyed $\mathrm{W}-\mathrm{Ni}$, as the milling progressed, the soft brass particles were plastically deformed to form aggregates and the $\mathrm{W}$ particles that fractured into nanosizes got embedded in this brass or coated with thin layer of brass. The product of the two stage ball milling was $\mathrm{W}-\mathrm{Cu}-\mathrm{Zn}$ composite powder of polygonal $\mathrm{W}$ grains dispersed in brass matrix.

\subsection{Microstructure of the Milled and Sintered Compacts}

The SEM of the milled powders are shown in Figure 3. From this figure, the $\mathrm{W}$ particles (lighter in colour) and the brass particles (darker in colour) are recognizable. For the powder milled for 4 and $8 \mathrm{~h}$, the reduction in particle size continues and the large aggregates of $\mathrm{W}$-brass become more homogeneous. The initial segregation of $\mathrm{W}$ and brass particles were eliminated after milling for $8 \mathrm{~h}$. Fine particles of $\mathrm{W}$ which are coated with thin brass layers agglomerate to form large W-brass aggregates as shown in Figure 3(b), Figure 3(d) and Figure 3(f). At the prolong milling for 12 and $14 \mathrm{~h}$, elongation of W particles due to deformation is visible, as shown in Figure 3(d) and Figure 3(f). The SEM of the sintered compacts are shown on Figure 4. From the SEM, the as-received compact is composed of deep, large and multiple holes. The holes are due to the evaporation of $\mathrm{Zn}$ and compact expansion. In the compacts milled for 8 and $12 \mathrm{~h}$, there is a uniform dispersion of $\mathrm{W}$ and brass particles as shown in Figure 4(b) and Figure 4(c). These compacts had the highest sintered density. Figure 4(d) shows the sintered compact milled for $14 \mathrm{~h}$. The presence of irregular holes in the grain boundaries is visible. This led to the reduction in the value of its sintered density.

\subsection{XRD Analysis}

The XRD results of the milled powder and the sintered composite compacts are shown in Figure 5. In the MA of the W-brass system, it is assumed that dissolution of a small amount of brass into $\mathrm{W}$ took place. The evidence for this is the shift in the $\mathrm{W}$ peak of W-brass sintered compacts. This shift in the XRD peak agrees with the findings of Alam [18] in the synthesis and characterization of W-Cu nanocomposites by mechanical alloying, where the dissolution of small amount of $\mathrm{Cu}$ into $\mathrm{W}$ caused a shift in the $\mathrm{W}$ peak in XRD analysis. The XRD peaks of the compacts milled for $8 \mathrm{~h}$ consist of CuO.81NiO.19 rather than the $\mathrm{W}$ and $\mathrm{Cu}$ peaks. As the milling was extended to $12 \mathrm{~h}$, the copper oxide peaks transformed to $\mathrm{Ni}_{3} \mathrm{Fe}$ intermetallic compounds. At $14 \mathrm{~h}$ of milling, the XRD of the sintered compact showed peak broadening due to particle size reduction, dislocation and MA induced strains. Additional peaks were observed as a result of oxides formation, $\mathrm{Fe}$ and $\mathrm{Cr}$ contamination. In the as-received compact, the $\mathrm{W}$ and $\mathrm{Cu}$ peaks are visible along with $\mathrm{CuWO}_{4}$ and $\mathrm{CuO}$ formation. The presence of these oxides might also be another factor that led to poor sinterability and low density. 


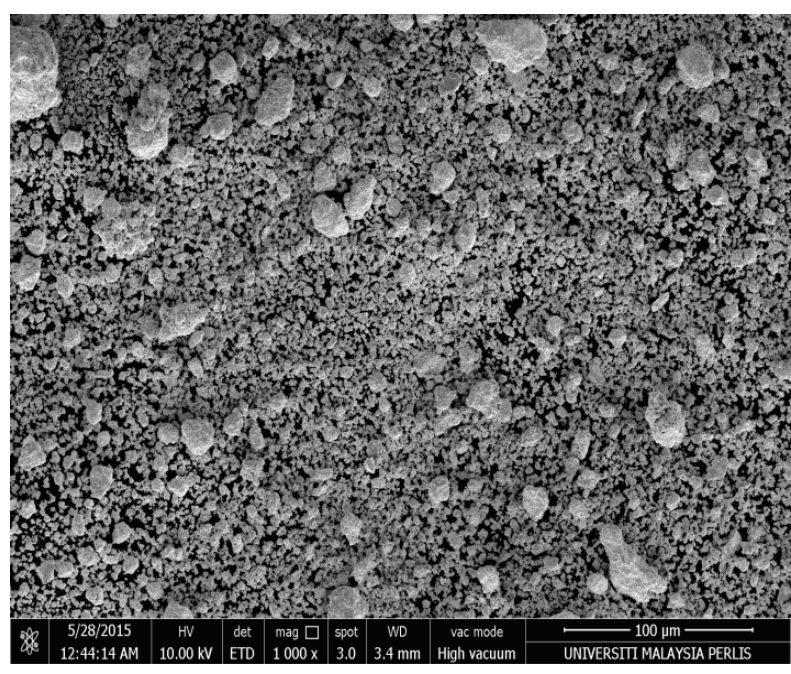

(a)

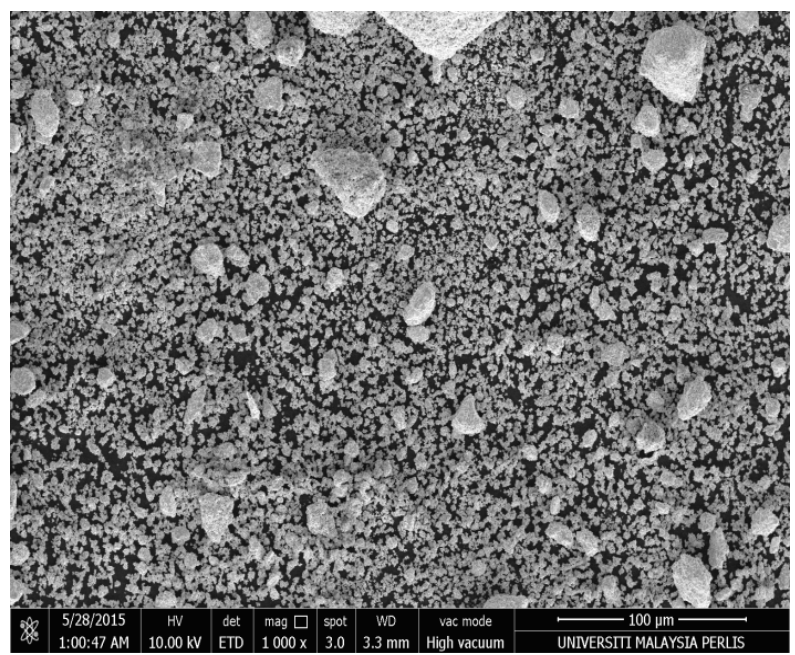

(c)

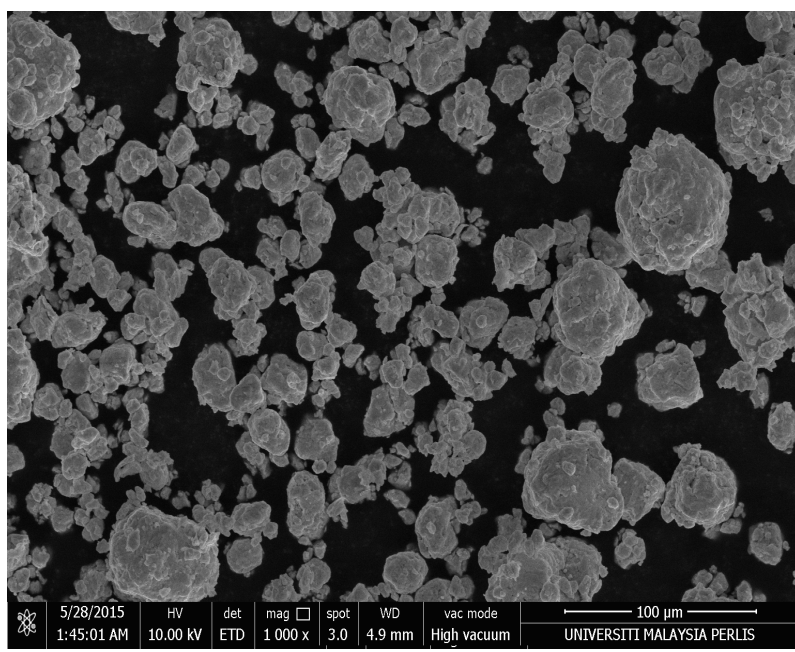

(e)

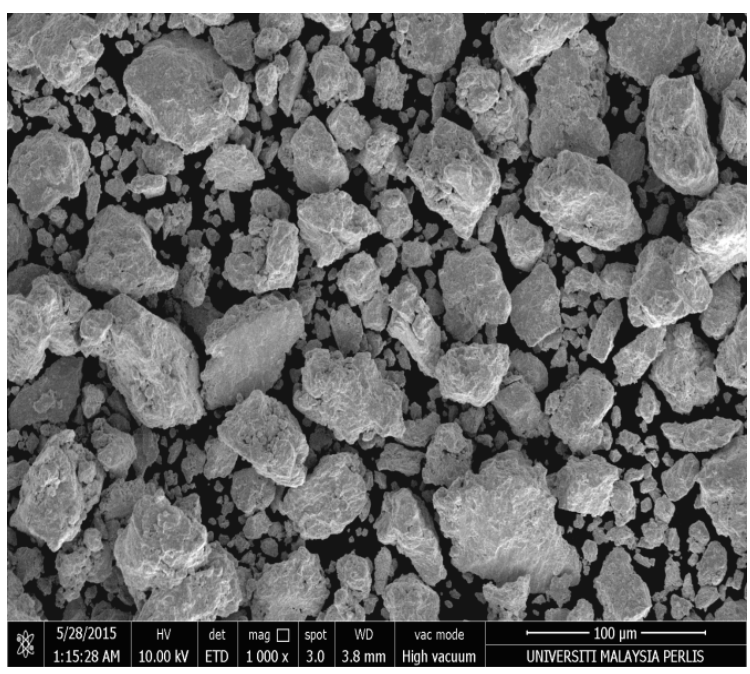

(b)

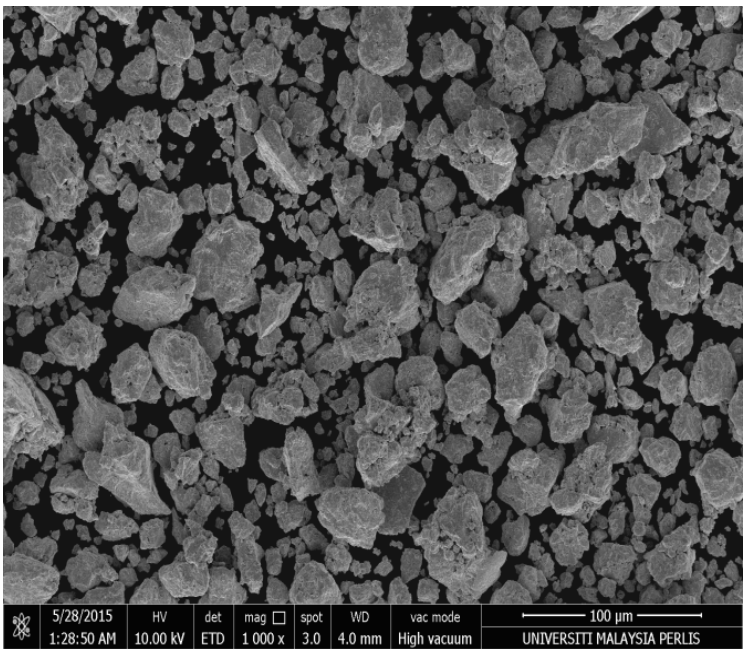

(d)

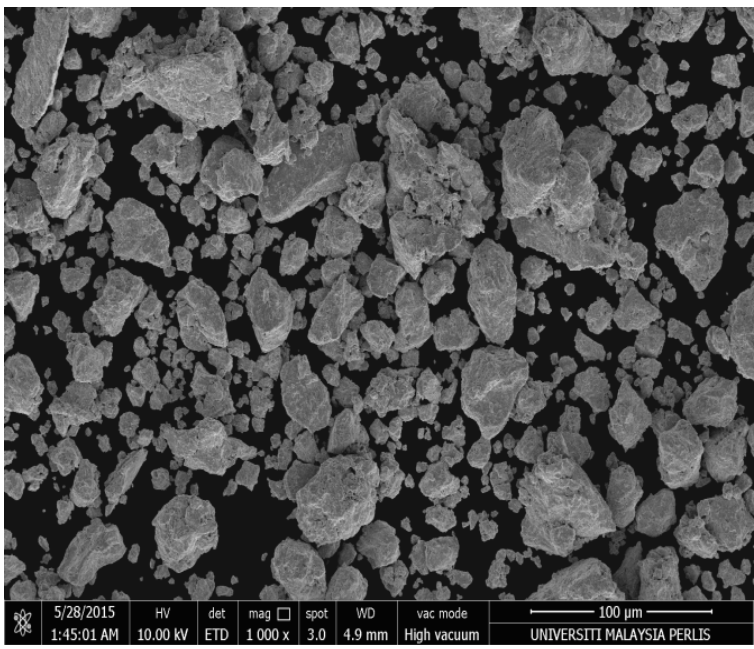

(f)

Figure 3. SEM of the milled powders. (a) W-Ni milled for $4 \mathrm{~h}$; (b) W-Ni-brass milled for $4 \mathrm{~h}$; (c) W-Ni milled for $6 \mathrm{~h}$; (d) W-Ni-brass milled for $6 \mathrm{~h}$; (e) W-Ni milled for $7 \mathrm{~h}$; and (f) W-Ni-brass milled for $7 \mathrm{~h}$. 


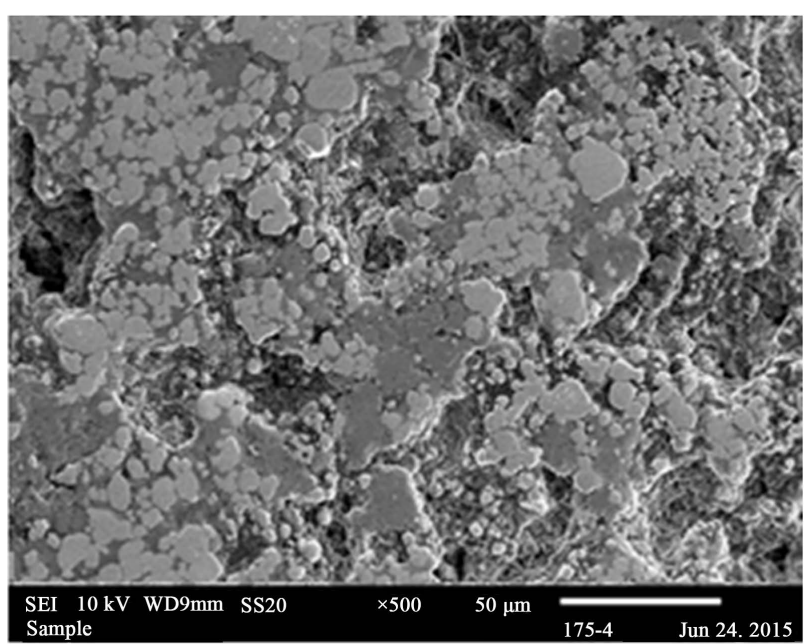

(a)

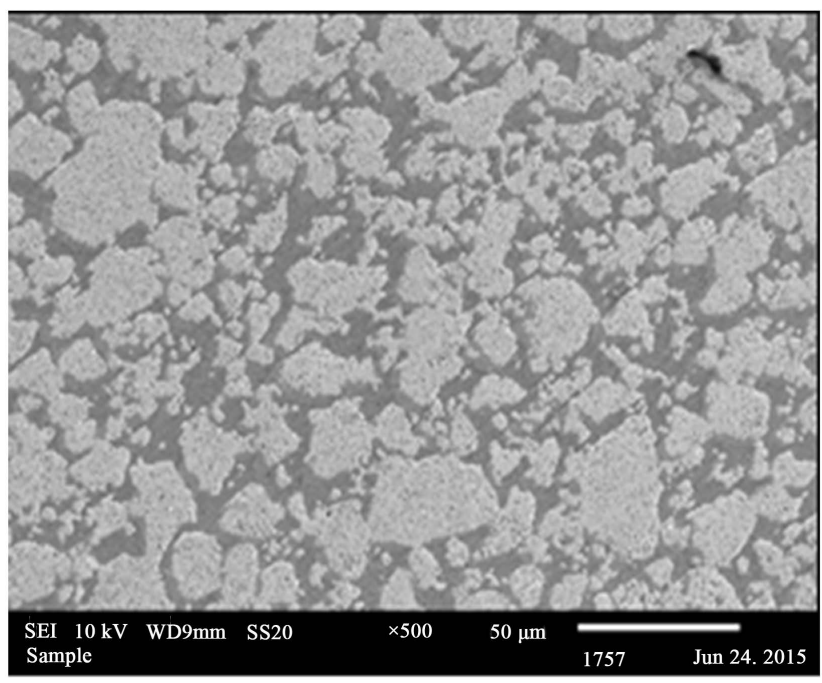

(c)

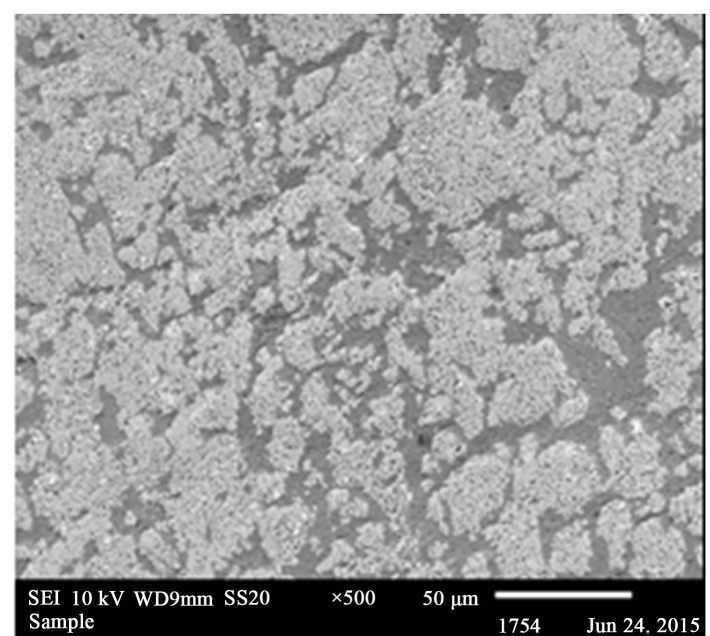

(b)

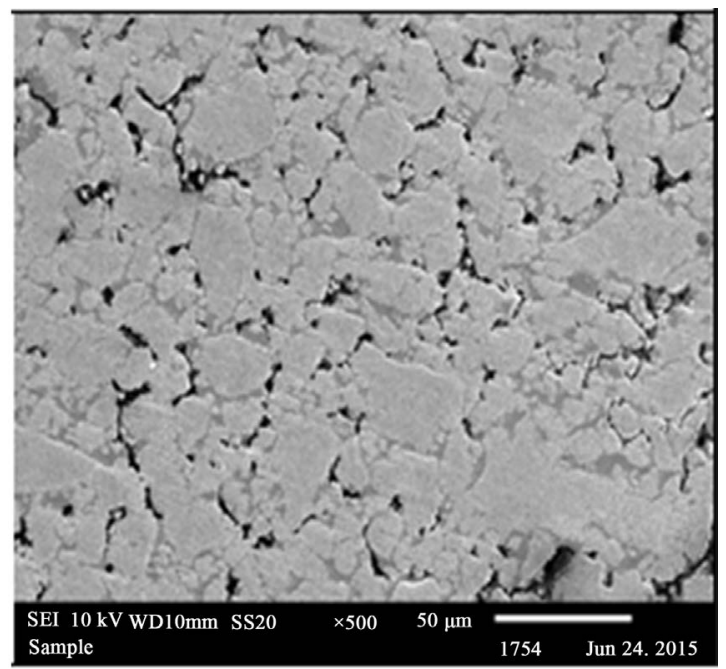

(d)

Figure 4. SEM of the sintered compacts. (a) as-received W-Ni-brass compact (without MA); (b) W-Ni-brass milled for 8 h; (c) W-Ni-brass milled for $12 \mathrm{~h}$; and (d) W-Ni-brass milled for $14 \mathrm{~h}$.

\subsection{Microhardness Results}

The relation between microhardness and milling time is shown in Figure 6. The lowest hardness value was observed in the as-received composite as a result of Zn evaporation and expansion and a corresponding lower sintered density. The highest hardness $(234 \mathrm{Hv})$ was obtained in the compact milled for $8 \mathrm{~h}$. After this, there was a decrease in hardness at 12 and $14 \mathrm{~h}$ milling time. In the milled samples generally, the higher hardness obtained might be as a result of uniform dispersion of $\mathrm{W}$ in the brass matrix. Due to homogeneous distribution of brass particles in MA process, formation of large pool was prevented; this enhanced the homogeneity of the microstructure. The decrease in hardness of the samples at 12 and $14 \mathrm{~h}$ might be as a result of residual porosities or intergrain embrittlement.

\section{Conclusion}

Mechanical alloying of W-2Ni-brass powders was carried out under pure argon. In the milled powders, the W peak was maintained after $14 \mathrm{~h}$ of milling, but the $\mathrm{Cu}$ peak broadened after $12 \mathrm{~h}$ and almost levelled out after $14 \mathrm{~h}$. The sintering was carried out at the temperature of $1150^{\circ} \mathrm{C}$, and relative sintered density of $67 \%, 98 \%, 97 \%$ and $94 \%$ TD was obtained from powders milled for $0,8,12$ and $14 \mathrm{~h}$ respectively. The highest density of $98 \%$ TD 


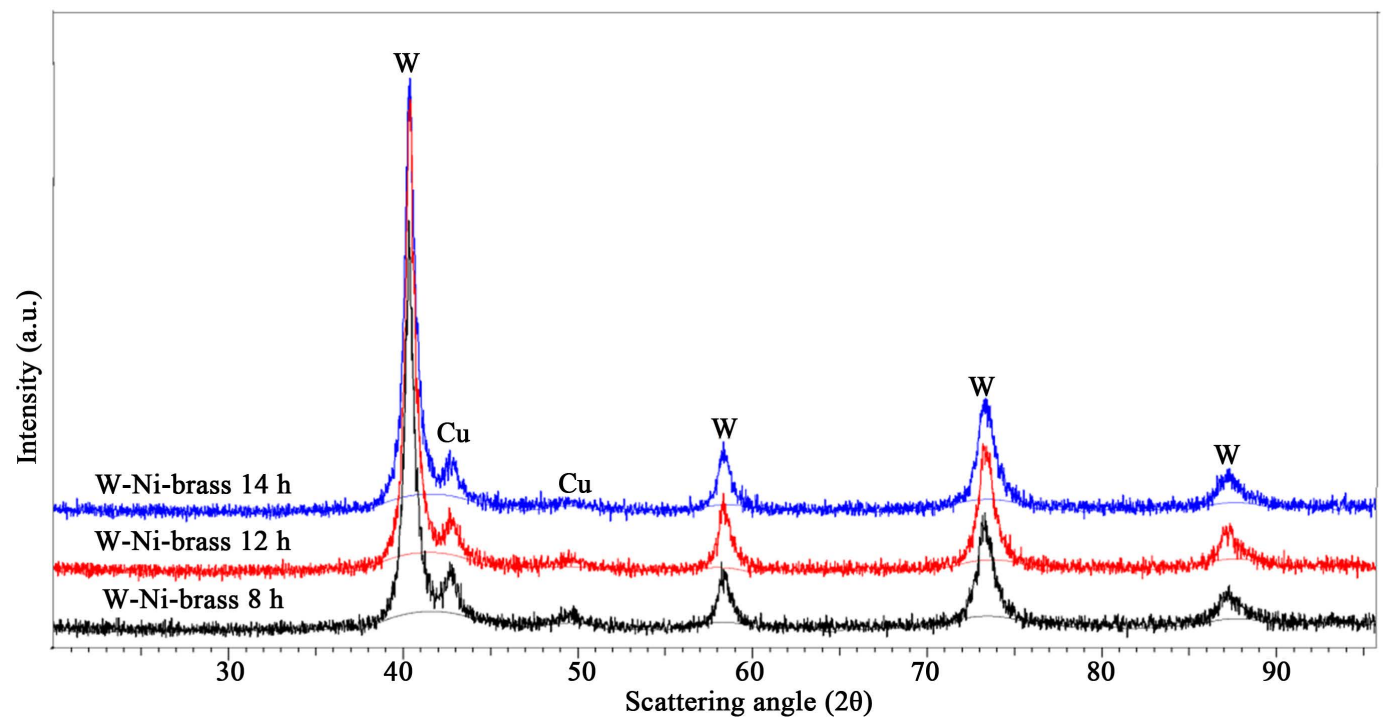

(a)

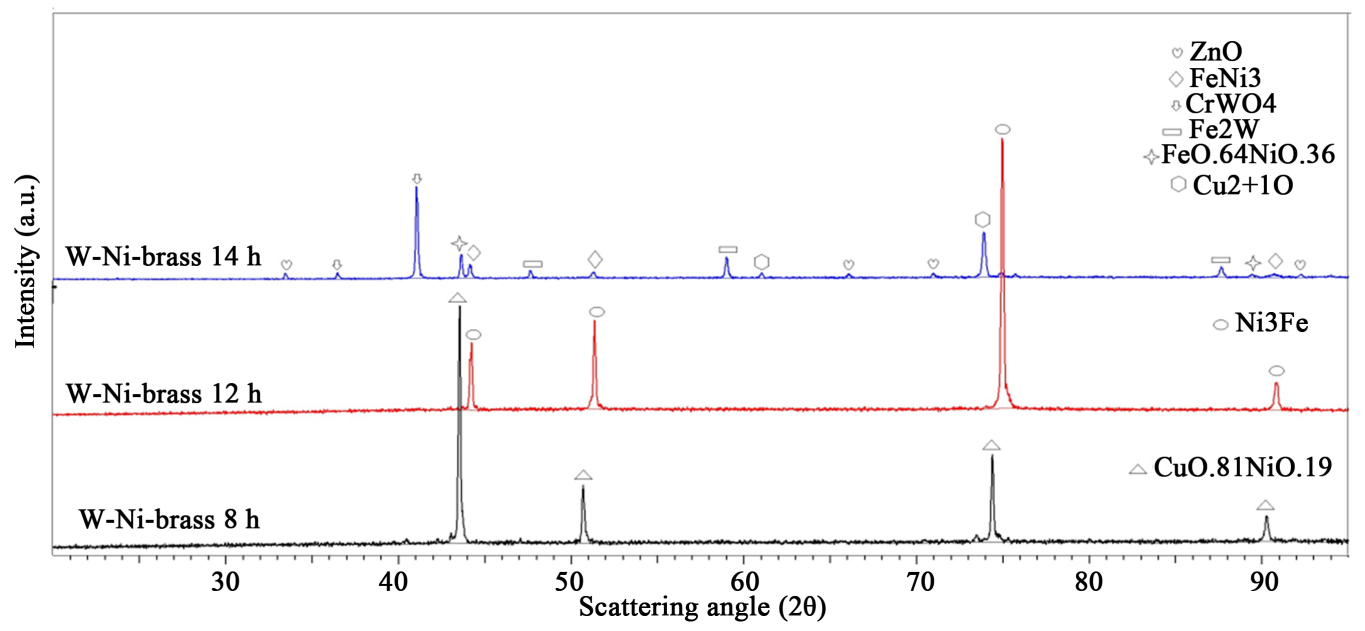

(b)

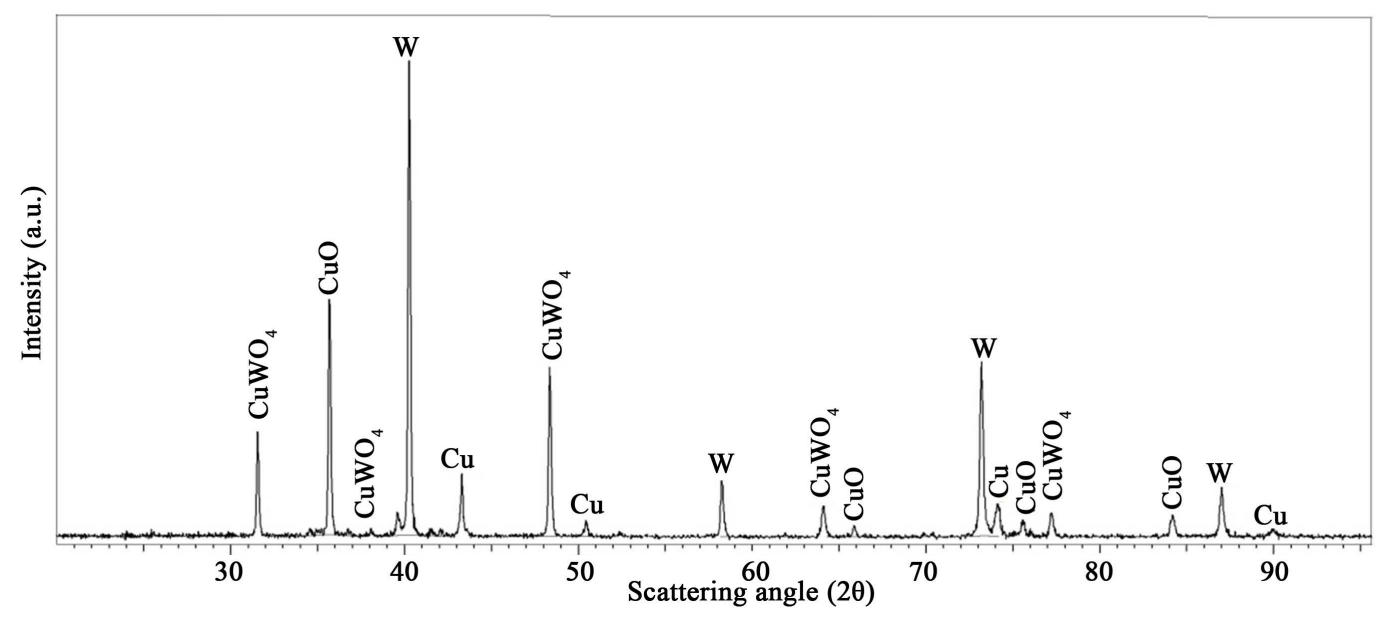

(c)

Figure 5. XRD results of (a) milled powder for 8, 12 and $14 \mathrm{~h}$; (b) sintered compacts from powders milled from 8 - 14 h; and (c) as-received compact. 


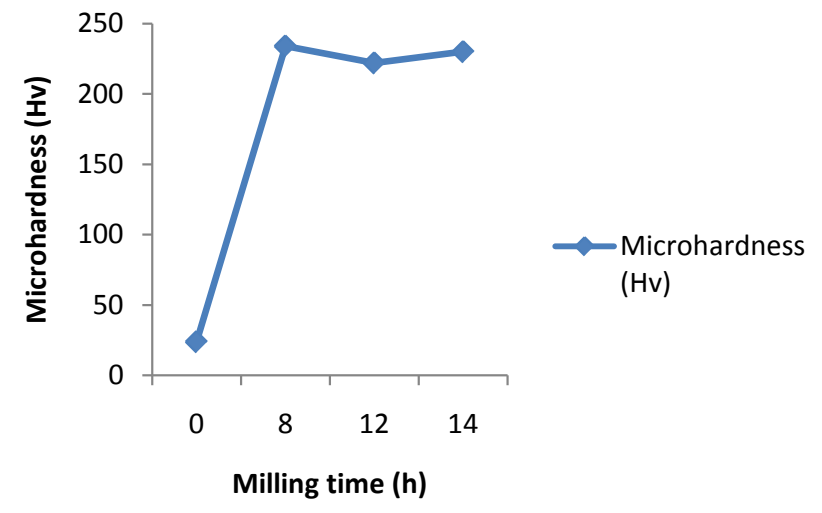

Figure 6. Variation of microhardness with milling time.

and hardness $(234 \mathrm{Hv})$ was achieved in the compacts milled for $8 \mathrm{~h}$. Longer milling time (12 - $14 \mathrm{~h})$ resulted in increased residual porosities, particle dislocation, MA induced strains and oxide build-up which decreased the sinterability. The as-received compact had deep, irregular and large holes as a result of $\mathrm{Zn}$ evaporation and compact expansion, which resulted in lower sintered density (lower than the green density) and hardness.

\section{References}

[1] Huang, L.-M., Luo, L.-M., Ding, X.-Y., Luo, G.-N., Zan , X., Cheng, J.-G. and Wu, Y.-C. (2014) Effects of Simplified Pretreatment Process on the Morphology of W-Cu Composite Powder Prepared by Electroless Plating and Its Sintering Characterization. Powder Technology, 258, 216-221. http://dx.doi.org/10.1016/j.powtec.2014.03.027

[2] Gowon, B., Mohammed, K.S., Jamaluddin, S.B., Hussain, Z., Aminu, A.D. and Lawal, Y.A. (2015) Experimental Studies on the Effects of Tin on the Densification of W-Brass Composites. Applied Mechanics and Materials, 754-755, 838-843.

[3] Mohammed, K.S., Rahmat, A. and Aziz, A. (2013) Self-Compacting High Density Tungsten-Bronze Composites. Journal of Materials Processing Technology, 213, 1088-1094. http://dx.doi.org/10.1016/j.jmatprotec.2013.02.006

[4] Luo, L.-M., Tan, X.-Y., Lu, Z.-L., Zhu, X.-Y., Zan, X., Luo, G.-N., et al. (2014) Sintering Behavior of W-30Cu Composite Powder Prepared by Electroless Plating. International Journal of Refractory Metals and Hard Materials, 42, 51-56. http://dx.doi.org/10.1016/j.ijrmhm.2013.10.012

[5] Ho, P.W., Li, Q.F. and Fuh, J.Y.H. (2008) Evaluation of W-Cu Metal Matrix Composites Produced by Powder Injection Molding and Liquid Infiltration. Materials Science and Engineering: A, 485, 657-663. http://dx.doi.org/10.1016/j.msea.2007.10.048

[6] Ardestani, M., Rezaie, H.R., Arabi, H. and Razavizadeh, H. (2009) The Effect of Sintering Temperature on Densification of Nanoscale Dispersed W-20-40\%wt Cu Composite Powders. International Journal of Refractory Metals and Hard Materials, 27, 862-867. http://dx.doi.org/10.1016/j.ijrmhm.2009.04.004

[7] Amirjan, M., Zangeneh-Madar, K. and Parvin, N. (2009) Evaluation of Microstructure and Contiguity of W/Cu Composites Prepared by Coated Tungsten Powders. International Journal of Refractory Metals and Hard Materials, 27, 729-733. http://dx.doi.org/10.1016/j.ijrmhm.2008.12.008

[8] Özkal, B., Upadhyaya, A., Öveçoölu, M.L. and German, R.M. (2004) Realtime Sintering Observations in W-Cu system: Accelerated Rearrangement Densification via Copper Coated Tungsten Powders Approach. European Powder Metallurgy, 40, 1-6.

[9] Abu-Oqail, A., Ghanim, M., El-Sheikh, M. and El-Nikhaily, A. (2012) Effects of Processing Parameters of TungstenCopper Composites. International Journal of Refractory Metals and Hard Materials, 35, 207-212. http://dx.doi.org/10.1016/j.ijrmhm.2012.02.015

[10] Hamidi, A.G., Arabi, H. and Rastegari, S. (2011) Tungsten-Copper Composite Production by Activated Sintering and Infiltration. International Journal of Refractory Metals and Hard Materials, 29, 538-541. http://dx.doi.org/10.1016/j.ijrmhm.2011.03.009

[11] Teodorovich, O. and Levchenko, G. (1964) Nickel in Tungsten-Copper Contacts. Soviet Powder Metallurgy and Metal Ceramics, 3, 476-479. http://dx.doi.org/10.1007/BF01194585

[12] German, R.M. (1996) Sintering Theory and Practice. Wiley-VCH, Weinheim, 568.

[13] El-Eskandarany, M.S. (2001) Mechanical Alloying for Fabrication of Advanced Engineering Materials. William An- 
drew Publishing/Noyes, New York.

[14] Buschow, K.H.J., Cahn, R.W., Flemings, M.C., Ilschner, B., Kramer, E.J. and Mahajan, S. (2001) Mechanical Alloying. In: Buschow, K.H.J., Cahn, R.W., Flemings, M.C., Ilschner, B., Kramer, E.J. and Mahajan, S., Eds., Encyclopedia of Materials—Science and Technology, Volumes 1-11, Elsevier, Amsterdam, 5230-5246.

[15] Suryanarayana, C. (2001) Mechanical Alloying and Milling. Progress in Materials Science, 46, 1-184. http://dx.doi.org/10.1016/S0079-6425(99)00010-9

[16] Meng, Y.F., Shen, Y.F., Chen, C., Li, Y.C. and Feng, X.M. (2014) Effects of Cu Content and Mechanical Alloying Parameters on the Preparation of W-Cu Composite Coatings on Copper Substrate. Journal of Alloys and Compounds, 585, 368-375. http://dx.doi.org/10.1016/j.jallcom.2013.09.100

[17] Yusoff, M. and Hussain, Z. (2013) Effect of Sintering Parameters on Microstructure and Properties of Mechanically Alloyed Copper-Tungsten Carbide Composite. International Journal of Materials, Mechanics and Manufacturing, 1, 283-286.

[18] Alam, S.N. (2006) Synthesis and Characterization of W-Cu Nanocomposites Developed by Mechanical Alloying. Materials Science and Engineering: A, 433, 161-168. http://dx.doi.org/10.1016/j.msea.2006.06.049

[19] Kim, J.-C. and Moon, I.-H. (1998) Sintering of Nanostructured W-Cu Alloys Prepared by Mechanical Alloying. Nanostructured Materials, 10, 283-290. http://dx.doi.org/10.1016/S0965-9773(98)00065-8

[20] Maneshian, M.H. and Simchi, A. (2008) Solid State and Liquid Phase Sintering of Mechanically Activated W-20 wt.\% Cu powder Mixture. Journal of Alloys and Compounds, 463, 153-159. http://dx.doi.org/10.1016/j.jallcom.2007.08.080

[21] Tsakiris, V., Lungu, M., Enescu, E., Pavelescu, D., Dumitrescu, Gh., Radulian, A. and Mocioi, N. (2014) Nanostructured W-Cu Electrical Contact Materials Processed by Hot Isostatic Pressing. Acta Physica Polonica A, 125, 348-352. http://dx.doi.org/10.12693/APhysPolA.125.348

[22] Shi, X., Yang, H. and Duan, X. (2008) Microstructure and Properties of W-15Cu Alloys Prepared by Mechanical Alloying and Spark Plasma Sintering Process. Journal of Wuhan University of Technology (Materials Science Edition), 23, 399-402.

[23] Kecskes, L.J., Klotz, B.R., Cho, K.C., Dowding, R.J. and Trexler, M.D. (2001) Densification and Structural Change of Mechanically Alloyed W-Cu Composites. Metallurgical and Materials Transactions A, 32, 2885-2893. http://dx.doi.org/10.1007/s11661-001-1039-0

[24] Ryu, S.S., Kim, Y.D. and Moon, I.H. (2002) Dilatometric Analysis on the Sintering Behavior of Nanocrystalline W-Cu Prepared by Mechanical Alloying. Journal of Alloys and Compounds, 335, 233-240. http://dx.doi.org/10.1016/S0925-8388(01)01805-9

[25] Igharo, M. and Wood, J. (1985) Compaction and Sintering Phenomena in Titanium—Nickel Shape Memory Alloys. Powder Metallurgy, 28, 131-139. http://dx.doi.org/10.1179/pom.1985.28.3.131

[26] Koo, J.-M., Araki, H. and Jung, S.-B. (2008) Effect of Zn Addition on Mechanical Properties of Brass Hollow Spheres. Materials Science and Engineering: A, 483-484, 254-257. http://dx.doi.org/10.1016/j.msea.2006.01.183

[27] Randall, M.G. (2007) Powder Processing. In: Groza, J.R. and Shackelford, J.F., Eds., Materials Processing Handbook, Chap. 25, CRC Press, Boca Raton, 1-23.

[28] Rajkumar, K. and Aravindan, S. (2009) Microwave Sintering of Copper-Graphite Composites. Journal of Materials Processing Technology, 209, 5601-5605. http://dx.doi.org/10.1016/j.jmatprotec.2009.05.017

[29] Boonyongmaneerat, Y. (2009) Effects of Low-Content Activators on Low-Temperature Sintering of Tungsten. Journal of Materials Processing Technology, 209, 4084-4087. http://dx.doi.org/10.1016/j.jmatprotec.2008.09.026 